\title{
The Factors That Influence the Efficacy of Celebrity Endorsement
}

\author{
Qi Chen ${ }^{1, *}$ \\ ${ }^{1}$ Grace Christian School, 1101 Buck Jones Rd, Raleigh, NC 27606, United States
${ }^{*}$ Corresponding author. Email: kchen@gracechristian.net
}

\begin{abstract}
With the development of Internet society, more and more celebrities begin to use their traffic to turn to the actual revenue. Many companies are also interested in the influence and the traffic of celebrities and invite them to endorse their products to stimulate their product sales. Many multimedia and platform data show that the endorser can indeed improve product sales. However, to maximize the positive impact of the endorser on product sales, companies need to select appropriate endorsers for their products. This research is aimed at how companies can choose an endorser who is most beneficial to their products. Through the research method of literature review, the whole study summarizes three criteria or aspects of the endorser that can most affect the efficacy of product sales: the profile, reputation, and expertise. These three aspects respectively represent the specific image or a setting of celebrities in front of the public, the moral image of celebrities in the public's eye, and the professionalism of celebrities in endorsing products. Using these three can help the companies have a standard for finding endorsers for their products to improve product sales.
\end{abstract}

Keywords: Celebrity Endorsement, Agent System, Role Model, Profile, Reputation, Expertise

\section{INTRODUCTION}

As the internet started becoming the dominant position, how money works is all about traffic. More and more celebrities start utilizing the traffic and turning it into actual revenue. How do these celebrities use their traffic to make money? One of the ways these celebrities use their traffic to make money is to turn their traffic into actual revenue by endorsing the company's products. Most of the stars' endorsements directly or indirectly have a certain impact on consumers' psychology and even consumer behaviour, and these impacts promote or stimulate the company's product sales. On April 12, 2021, Mengniu Dairy's upscale ice cream brand "TilanShengxue" officially announced Xiao Zhan as its endorser. Within 30 minutes after the official announcement, the orders of the ice cream on the online platform exceeded more than 100000 pieces and gained exceeded 23 million yuan [1]. Celebrity endorsement advertising not only increases brand sales volume but also creates huge benefits for the company. The participation of celebrities leads to sales can be easily determined.

However, nowadays, society has so many ways to endorse the products through the internet, Tik Tok,
Instagram, Snapchat and the company can invest their money on the influencers for endorsing, which is cheaper than finding a celebrity or a star. According to the data report and analysis from the media data centre, in 2019, the conversion rate of all kinds of KOL goods in China exceeded $70 \%$. Among them, the star endorsement publicity has the highest conversion rate of goods, which is $84.3 \%$; Followed by the live broadcast platform, the anchor with goods conversion rate was $83.1 \%$, while the microblog big $\mathrm{V}$ with goods conversion rate was the lowest, which was $75.3 \%$ [2]. From this data analysis, we can see that the efficiency of improving the sales volume of products endorsed by stars is the best. This is why companies value celebrity endorsement as their main advertising method.

The customers as an important role in the marketing, and the company must know celebrity endorsements have a considerable attraction for the customers to purchase their products. Although some companies have amazing products, since these are their products, there is little credibility to let customers believe them, known as interested parties with bias. So, they have to have an impartial third party to prove that their products are actually good. Here, to analyse how consumers are affected by the endorser, three aspects are applied: the profile, reputation, and expertise. This research can be 
used for companies to measure the standard of if the endorsing star is suitable for their products.

\section{PROFILE}

The celebrity profile is a big part of the endorsement because if the company finds the celebrity with a profile that just matches their product, it will promote the audiences' interest in purchasing the product. Otherwise, they will lose interest. According to the article written by Cheng Juan, she explains that profile is a character set, and profile originally refers to cartoon, animation, character setting in the game, appearance, character and other elements [3]. It is now used to refer to the specific public image setting of stars in front of the public. At the same time, she also pointed out that human design is a narrative text. Celebrities and stars' images are shaped texts. Their experiences reported news and interpreted works will construct an image in the public's eyes, which is their profile. In this research, the profile is the identity of the celebrity in front of the public. Their interest, personality and hobbies are all part of their profile which the company can choose who has the best profile to match their product. Like how Cheng Juan demonstrates the profile as a narrative text, the profile is an celebrity agent. It's the role of the celebrity that exist in the public or the society. Based on the statement of Francis Steen, he says the stories have a narrative structure: an agent with certain resources is striving for a goal. Still, they will face certain obstacles, and the drama is about how the agent uses his or her limited resources to try to overcome the obstacles and reach the goal [4]. This structure is called the Agent system. Agent system is a cognitive structure that tracks our status and progress as agents. It includes who we are, what our resources are, what goals we have and what obstacles we face. This is the same as how celebrities create their profiles. Profile first is the identification of the celebrity. It tells the public who they are; it's also the exhibition of what the celebrity has experienced, their news, their work which has been done in front of the public and that's what they have as resources to build their profile; their goal the building up the profile is also the reason why they start it, they want to use their profile to success and promoting the endorsement is one of their ways; the obstacle they are facing is to let the public believe the profile they created, they need to drag the people into the agent system they created. The most basic agent system is children's play. While they were playing, they brought themselves into the role of the game. Even if the mode of the game was played by the children themselves, in the process of playing the game, they all believed that they were eagles, and their characters were going to catch the chicks played by other children. They perform the personal design of stars. Their fans are the audience of the play. Stars and celebrities are the actors who perform to the fan audience with their own "resources" on the stage. A successful play can immerse the audience without discovering that they are fake or just pretending the role, and that's exactly the goal of the profile.

Why the profile is an important factor for the efficacy of the endorsement? Since the company look for the endorser is because they are the biased party and they need credibility from the celebrity who endorses the product, if the celebrity's profile just matches the product's concept, people will believe that the quality of this product is good, so they want to buy it. For instance, a company thatproduces milk powder for babies, if they just go looking for who is the most popular songs right now, the product won't be promoted very well because "the most popular singer"doesn't match the milk powder's concept, people have no reason to put more credibility on the milk powder will be a good choice for their babies. However, if they find a celebrity with the agent of the responsible mother who takes great care of her children, the audience will trust the product better. Therefore, a good choice of celebrity to endorse the product can stimulate the sales volume.

\section{REPUTATION}

In this research, reputation represents how well the endorser is shown in front of the public in a moral way. Based on the endorser's reputation, consumers' purchase behavior will be affected. According to Shang Daji's article, it demonstrates that if a star's own reputation is damaged due to a scandal, the behavior of the star endorser conflicts with the set of values of consumers, resulting in a decrease in consumers' trust in the star and indirectly affecting the credibility of the products they endorse, because the company's finding a star as a spokesperson is to improve its credibility [6]. Research shows that, especially when consumers think that the behavior of celebrities is wrong or their behavior is a disgrace or harm to the whole society, stars need to be responsible for their behavior. Therefore, if a star spokesperson makes a decision that consumers think will disgrace society, it is certain that it will greatly reduce the sales of the endorsed products.

Furthermore, the reputation contains not only their own personal reputation, but the product previously endorsed by celebrities is also very important. It is also an investigation of consumers' trust in this product. According to the data analysis in "the influence of star endorsement on consumers' purchase behavior", we can see that $58 \%$ of the respondents, over half of the responders, will no longer believe in the authenticity of the advertisement [7]. It can be seen that the authenticity of star endorsement advertising has a great impact on consumers' purchase behavior. To be more specific, for example, Giorgio Armani invited Jackson Yi as their endorser for their cosmetics brand. After Jackson Yi endorse their product, many Armani lipsticks are out of stock in the online store of Giorgio Armani cosmetics. 
People pay more attention to Armani makeup than before. Not only Jackson's fans will buy, but also those who want to buy make-up but hesitate to do so. Because of Jackson Yi, those non-fans have the urge to buy Armani make-up. According to the 2019 Sina Weibo star white paper, Jackson Yi won the double champions of the star business value list in the second half. The whole year, this report shows the common republic have a preference on the product Jackson endorsed because they are willing to buy the goods, so Jackson's commercial value can be so high [8]. The reason for this phenomenon is because his reputation is so well among the public. According to the article written by Cheng Cheng, this article displays that Jackson $\mathrm{Yi}$ is a great idol and a powerful actor [9]. He has participated in several TV dramas, but the most influential is the films he starred in. One of them, Better Days, has been highly praised by society and even caused a big wave in the film industry. No one at that time thought that a young man who had not reached the age of twenty could have such a superb acting skill, and he could easily win the imperial examination. Jackson also received extensive attention from the film media because of this film, and many directors who cooperated with him praised him. From many interviews, the public can see a dedicated, hardworking and diligent Jackson in the performing arts career. In the reality show "this is street dance", Jackson served as the judge. No matter who challenged him, he did not timidly meet the challenge. What the public sees is responsible, responsible and brave. Because Jackson shows a very positive side in front of the public, many people will like him and think he is trustworthy even if they are not his fans. Therefore, the public believes that the products he endorses are trustworthy, which is why Armani's cosmetics sales have increased by leaps and bounds. Apparently, an endorser with a very good reputation can help the sales of the company's products.

\section{EXPERTISE}

How much of the expertise the endorser has should be a factor to consider because this relates to if the endorser knows exactly if this product has a good quality or not. And If the endorser is an expert in endorsing the product in the public's eyes, it can increase consumers' trust in the product and make the product have a considerable sales volume. Expertise is actually the amount of product knowledge, and product knowledge is the relevant knowledge that consumers can rely on when choosing products to solve their consumption problems[10].In this research, the endorser's expertise is the knowledge the endorser has about the product or in the same field. According to the article published by Zhang Ning, Yu Liqin and Zheng Fucheng, when consumers are not familiar with the product field endorsed by the endorser and do not have rich product knowledge, an endorser with professional knowledge can produce a better attitude towards the product [10]. So, the more expertise the endorser has, the more consumers will be willing to buy the company's product. This can relate to the concept of the Role Model. From the Francis study, role models must be available in our social environment, be like ourselves along some dimension, and be successful [11]. Corresponding to the reason why the endorser can direct people to buy the product, it's because when people see the endorser, he or she is endorsing something that the consumer is interested with, if the endorser is known as a sort of professional in the product's fields, people tend to have a desire to imitate his or her step to purchase that product. Because role models provide a shortcut to learning and allow us to acquire skills that may succeed in our own social environment; when the consumer is looking for the right product, if a knowledgeful endorser endorses a product since they know the endorser is professional in this product's area, the consumers don't have to learn all the information about the expertise area, they will just follow the endorser's guide because they believe the endorser can lead them to buy a satisfying product successfully [11]. For instance, Li Jiaqi is a very famous cosmetics live streamer. The beauty products endorsed in his live stream usually have a very large sales volume. Based on the new report in Tencent News, on the first night of double 11, the war report broadcastedlives on Taobao said that Li Jiaqi sold more than 10.6 billion Yuan [12]. This amazing number of sold products is shocked, but how did Li Jiaqimake this happen? One of the strategies or reasons for this is expertise. According to the research by BoyaSu, Li Jiaqi was a senior BA of L'Oreal before, so his years of sales experience in the field of beauty has accumulated rich professional knowledge for him [13]. Through his extensive research in the field of beauty, he has also produced professional beauty content for users and become a beauty live streamer recognized by consumers. Because Li Jiaqi has professional knowledge of beauty makeup, which reduces the risk of "try mistake" of consumers. Thesespecialities have become the reason why users love and support the products recommended by Li Jiaqi. At the same time, he is also the Guinness record holder for lipstick, highlighting his cosmetics professionalism.

\section{CONCLUSION}

This research discusses that since celebrities use the Internet to realize traffic in this Internet era, how the companies should find the endorser to improve the sales of their products, the efficacy of celebrity endorsement. Because the data of major platforms show that after most brands find the endorser, product sales have increased, which is what the company needs. So, this research shows what factor of the endorser can affect the company sales. After understanding these aspects, the company can judge the celebrities they are suitable 
for endorsing their products, to stimulate the sales of products to the greatest extent.

For the first factor, profile, is suggested that the company find an endorser that can match its product image, and the selected standard is the image of the endorser in front of the public and the agent system they create. Finding the agent system that best fits its product image can immerse people in the agent system the endorser created the most. At that time, people will trust the product and give credit to the company's product which gives full play to the influence of endorsers on product sales.

Moreover, endorsers' reputation is also directly related to the sales of the products they endorse. If the endorser's reputation is damaged, it indicates that the endorser's behaviour conflicts with consumers' values. Consumers are no longer willing to trust the endorser's endorsed products, which will lead to the loss of product sales. On the contrary, if the company hires endorsers with a serious reputation in public, it will positively affect consumers' trust in the products and make them believe in the quality of the company's products. Therefore, an endorser with an excellent reputation should also be the standard considered by the company.

Finally, the endorser's expertise should also be considered because consumers can trust an endorser with a deep understanding of the endorser's products. In the minds of consumers, this kind of endorser is their role model at the time of purchase. Therefore, customers will feel that these endorsers with professional knowledge can minimize their risk of buying inferior goods and lead them to buy the most satisfactory goods to the greatest extent.

From this study, we can see that endorser plays a very important role in commodity sales. Some consumers even buy products just because of the endorser itself, which actually subverts the original consumer culture. At first, the company hired an endorser to make the public pay attention to the product itself because of the influence of the endorser. However, with the increasing impact of endorsers on product sales, some companies even spend a lot of money to invite stars with huge traffic to endorse instead of studying and developing better products. Although celebrities want to maintain a good profile and reputation, a similar situation inevitably occurs. In future research, think about which has a greater influence on the consumers? The endorser or the product itself? Why did this happen?

\section{REFERENCES}

[1] Tencent(n.d.) Xiao Zhan's best endorsement has driven huge sales, and the 8th endorsement in the year was popular Xiao Zhan's best endorsement has driven huge sales, and the 8th endorsement in the year was popular_ Tencent News (n.d.). Retrieved October 24, 2021, from https://new.qq.com/rain/a/20210413A03HT600.

[2] KOL industry data analysis: in 2019, the conversion rate of Chinese star endorsement promotional tapes was $84.3 \%$ - AI media. AI media - the leader of the research and analysis report of new economy industry (n.d.). Retrieved October 24,2021 , from https://www.iimedia.cn/c1061/67914.html.

[3]Cheng Juan (2021). Human design as Fictional Narration: an observation of the phenomenon of star culture. Human design as Fictional Narration: an observation of the phenomenon of Star Culture China HowNet. Retrieved October 24, 2021, from https://kns.cnki.net/kcms/detail/detail.aspx?dbcode $=$ CCJD $\&$ dbname $=$ CCJDLAST $2 \&$ filename $=\mathrm{ZWW}$ W202101032\&uniplatform $=$ NZKPT\&v $=b N U b Z k v$ iym5CFpciC\%25mmd2B7NZXBxXpR1wCF5qQk d4ReoSVHuGibl4LrlUqJckqmqjz4C.

[4] Francis Steen(2021), the Agent System [PowerPoint slides], University of California, Los Angeles, https://edstem.org/us/courses/7129/resources?down load $=10141$

[5] PAIKE: new consumer promotion officer. (2021). Annual inventory of brand star marketing: six new marketing trends, who is the most out of the circle. Retrieved October 24, 2021, from https://m.thepaper.cn/baijiahao_10742918.

[6] Shang Daji. (2012). How does the celebrity spokesperson scandal affect consumer attitudes How does the celebrity spokesperson scandal affect consumer attitudes-- Master's thesis of Huazhong Agricultural University in 2012. Retrieved October 24, 2021, from http://cdmd.cnki.com.cn/article/cdmd-105041012457534.htm.

[7] Quan qingying; Liang Qiang; Sun Yan (2018). The impact of star endorsement on consumers' purchase behavior. The impact of star endorsement on consumers' purchase behavior - Baidu LibraryRetrieved October 24, 2021, from https://wenku.baidu.com/view/1aca82fbedf9aef894 1ea76e58fafab068dc44ab?fr=xueshu.

[8] C2cc media (n.d.). Yiyang Qianxi, a man who is more fearful than Li Jiaqi, speaks for Armani as a king of goods. Retrieved October 24, 2021, from http://www.c2cc.cn/news/10003948.html.

[9] Cheng Cheng(n.d.). Jackson Yi, From Idol to Actor. Retrieved October 24, 2021, from https://kns.cnki.net/kcms/detail/detail.aspx?dbcode $=$ CJFD $\&$ dbname $=$ CJFDLASN2021 $\&$ filename $=$ DY 
TX2021Z1011\&uniplatform=NZKPT\&v=hpkG5f TI\%25mmd2FmC\%25mmd2BFWUDkFFbMqRF3 fAxg3slPLE3fOcqux66TOXyoes8cEmNXiBlxBv $\mathrm{Q}$

[10] Zhang Ning; Yu Liqin; Zheng Fucheng; (n.d.). The Effects of Spokes-characters Traits on Brand Attitude---The moderator role of product knowledge" - China HowNet. Retrieved October 24, 2021, from https://kns.cnki.net/kcms/detail/detail.aspx?dbcode $=$ CCJD $\&$ dbname $=$ CCJDLAST2 $\&$ filename $=$ LJGL2 01802007\&uniplatform $=$ NZKPT\&v=sbpUGBtJLb q15KAbn6pDQfpGClQPfruzlG40WmGS7CEKLN ZAiP944rrxIRaOebDB.

[11] Francis Steen, the Agent System [PowerPoint slides], University of California, Los Angeles, https://edstem.org/us/courses/7129/resources?down load $=10387$

[12] Tencent News. (2021). Li Jiaqi sold 10.6 billion SKPs in one night. We underestimated double $11_{-}$ Tencent News.Retrieved October 24, 2021, from https://new.qq.com/rain/a/20211024A03JIK00.

[13] Su Boya.(2020). Research on the Communication Strategy of "Li Jiaqi' Personal Brand. --Master's thesis of Suzhou University in 2020.Retrieved October 24, 2021, from http://cdmd.cnki.com.cn/Article/CDMD-102851020152972.htm. 